\title{
Globe
}

\section{Un parti pris sexuel. Sexualité et masculinité dans la revue Parti Pris}

\section{A Sexual Revolution. Sexuality and Masculinity in the Periodical Parti Pris}

\section{Jean-Philippe Warren}

Volume 12, numéro 2, 2009

Images et représentations de la sexualité au Québec

URI : https://id.erudit.org/iderudit/1000711ar

DOI : https://doi.org/10.7202/1000711ar

Aller au sommaire du numéro

Éditeur(s)

Globe, Revue internationale d'études québécoises

ISSN

1481-5869 (imprimé)

1923-8231 (numérique)

Découvrir la revue

Citer cet article

Warren, J.-P. (2009). Un parti pris sexuel. Sexualité et masculinité dans la revue Parti Pris. Globe, 12(2), 129-157. https://doi.org/10.7202/1000711ar

\section{Résumé de l'article}

Depuis plusieurs années, l'histoire de la sexualité au Québec s'est enrichie de nombreuses publications qui couvrent l'ensemble des $\mathrm{XIX}^{\mathrm{e}}$ et $\mathrm{XX}^{\mathrm{e}}$ siècles. Il semble néanmoins que la période des années 1960 , pourtant très riche du point de vue du bouleversement des moeurs, ait reçu jusqu'ici une attention mitigée de la part des chercheurs. Elle correspond pourtant à une période d'intenses remises en question de la sexualité, non seulement en continuité avec les tendances libérales à la privatisation du corps et la montée de l'individualisme et de l'intimité, mais à l'intérieur même du courant nationaliste qui n'hésite pas à recycler la sexualité dans sa rhétorique émancipatrice. C'est du moins ce qui ressort d'une lecture des numéros de Parti pris. Dans les pages de cette revue, les auteurs s'interrogeaient sur la sexualité des Canadiens français, sur leurs valeurs, leurs pratiques et leurs inhibitions. Ils replaçaient la question de la sexualité québécoise dans un cadre sociologique et envisageaient sa solution de manière collective. Pour les collaborateurs de Parti pris, un nouvel érotisme allait permettre non seulement l'épanouissement plein et entier de chaque individu, mais le libre déploiement de l'imaginaire national. S’inscrivant dans l'optique de la décolonisation tout en recyclant plusieurs motifs phallocratiques, ils trouvaient dans le sujet de la sexualité matière à revoir toujours le même problème de l'aliénation et de l'exploitation des Canadiens français. La libération sexuelle, vue à travers un prisme fondamentalement masculiniste, représentait, aux yeux de ces utopistes, une facette essentielle de la libération humaine globale. 


\title{
UN PARTI PRIS SEXUEL. SEXUALITÉ ET MASCULINITÉ DANS LA REVUE PARTI PRIS
}

\author{
JEAN-PHILIPPE WARREN \\ Université Concordia \\ $4+4+4+4+4+4+4+4+4+4+4+4$
} Résumé - Depuis plusieurs années, l'histoire de la sexualité au Québec s'est enrichie de nombreuses publications qui couvrent l'ensemble des $\mathrm{XIX}^{\mathrm{e}}$ et $\mathrm{XX}^{\mathrm{e}}$ siècles. Il semble néanmoins que la période des années 1960 , pourtant très riche du point de vue du bouleversement des mours, ait reçu jusqu'ici une attention mitigée de la part des chercheurs. Elle correspond pourtant à une période d'intenses remises en question de la sexualité, non seulement en continuité avec les tendances libérales à la privarisation du corps et la montée de l'individualisme et de l'intimité, mais à l'intérieur même du courant nationaliste qui n'hésite pas à recycler la sexualité dans sa rhétorique émancipatrice. C'est du moins ce qui ressort d'une lecture des numéros de Parti pris. Dans les pages de cette revue, les auteurs s'interrogeaient sur la sexualité des Canadiens français, sur leurs valeurs, leurs pratiques et leurs inhibitions. Ils replaçaient la quescion de la sexualité québécoise dans un cadre sociologique et envisageaient sa solution de manière collective. Pour les collaborateurs de Parti pris, un nouvel érotisme allait permettre non seulement l'épanouissement plein et entier de chaque individu, mais le libre déploiement de l'imaginaire national. S'inscrivant dans l'optique de la décolonisation tout en recyclant plusieurs motifs phallocratiques, ils trouvaient dans le sujet de la sexualité matière à revoir toujours le même problème de l'aliénation er de l'exploitation des Canadiens français. La libération sexuelle, vue à travers un prisme fondamentalement masculiniste, représentait, aux yeux de ces utopistes, une facerte essentielle de la libération humaine globale.

$$
\div \div
$$

1. Je tiens à remercier Louise Bienvenue, Marc Lafrance, Jean-Marc Piotte ainsi que les deux évaluateurs anonymes de la revue Globe pour leurs judicieux commentaires sur une version préliminaire de ce rexte. 


\section{A Sexual Revolution. Sexuality and Masculinity in the Periodical Parti Pris}

Abstract - The literature on the history of sexuality in Quebec has rapidly grown in the past few years and now covers most of the XIXth and XXth centuries. Yet, the sixties, a period of profound cultural changes, have received scant attention from scholars. This decade nevertheless corresponds to an intense redefinition of sexual relations and more, not only by accentuating the liberal trends towards the privatization of the body and the rise of individualism and intimacy, but by also accompanying a nationalist movement that did not hesitate to recycle some themes related to sexuality within its own emancipatory rhetoric. A reading of Parti Pris (1963-1968) confirms such a view. In the pages of this periodical, some authors attempted to challenge French Canadians' sexuality, questioning their values, their behaviour, and their inbibitions. They situated the question of sexuality in an ideological frame and envisioned a collective solution to its alleged perversions. For the Parti Pris collaborators, a new erotism would not only enable individual achievement, but also free the development of the national imaginary. Following the prevalent discourse of decolonisation, while recycling many phallocratic ideas, they found in the subject of sexuality the occasion to reflect on the recurrent problem of alienation and exploitation of French Canadians. The sexual liberation, seen through a fundamentally masculinist lens, represented, in the minds of these utopian thinkers, an essential dimension of a global buman liberation.

$+4+4+ \pm+4+4+4+4+4+4+4$

Depuis plusieurs années, l'histoire de la sexualité au Québec s'est enrichie de publications qui couvrent l'ensemble des $\mathrm{XIX}^{\mathrm{e}}$ et $\mathrm{XX}^{\mathrm{e}}$ siècles ${ }^{2}$. Il semble néanmoins que la période des années 1960 et 1970 , pourtant très riche du point de vue du bouleversement des mœurs, ait reçu jusqu'ici une attention mitigée de la part des chercheurs qui, peut-être, dévaluent la littérature critique produite par les révolutionnaires tranquilles, faute d'y reconnaître quelque véritable originalité ${ }^{3}$. Entre l'aggiornamento sexuel des années 1950, qui se déroule sourdement et croît dans les interstices du pouvoir religieux et juridique, et l'inclusion dans le discours dominant des années 1980 de pratiques sexuelles autrefois confinées dans les marges de la

$$
+4
$$

2. Pour un bon tour d'horizon de cette littérature, lire Jeffrey VACANTE, "Writing the History of Sexuality and "National" History in Quebec", Journal of Canadian Srudies, vol. 39, $n^{\circ} 2$, printemps 2005, p. 31-55. Mon article sur Parti pris reprend plusieurs conclusions déjà formulées par le même aureur dans "Liberal Nationalism and the Challenge of Masculinity Studies in Quebec", Left History, vol. 11, $\mathrm{n}^{\circ}$ 2, automne 2006, p. 96-117.

3. En 1998, Élise SALAON pouvait ainsi écrire: "La sexualité, et en parriculier sa représentation littéraire, a éré l'une des forces incontournables qui ont ébranlé l'édifice social du milieu de notre siècle. Force qui, étrangement, n'a jamais été reconnue dans le discours critique" "Érotisme littéraire et censure: la révolution cachée", Voix et images, vol. 23, $n^{\circ} 2,1998$, p. 299). 
déviance, les années 1960 semblent peu propices à une réflexion globale. Cette impression est trompeuse, la Révolution tranquille correspondant en fait à une période d'intenses remises en question de la sexualité, non seulement en continuité avec les tendances libérales à la privatisation du corps et la montée de l'individualisme et de l'intimité, mais à l'intérieur du courant nationaliste qui n'hésitait pas à recycler la sexualité dans sa rhétorique émancipatrice.

C'est du moins ce qui ressort d'une lecture des numéros de Parti pris (1963-1968), une revue dont Marcel Rioux a pu dire qu'elle avait incarné de manière exemplaire les aspirations de la jeunesse en révolte: "De toutes les publications de gauche de cette période, il semble bien que c'est Parti pris qui a eu la plus grande audience et le plus d'impact sur la société québécoise ". Ses principaux collaborateurs ont donné diverses interprétations de l'idéologie véhiculée dans les 53 numéros de ce périodique, Pierre Maheu insistant sur l'aspect révolutionnaire, Paul Chamberland sur l'aspect anthropologique et Jean-Marc Piotte sur l'aspect politique ${ }^{5}$. D'autres chercheurs ont fait paraître des travaux sur des dimensions plus littéraires du périodique, puisque maints poètes et écrivains y ont publié leurs poèmes et leur prose ${ }^{6}$. La critique culturelle n'était pas absente, loin de là, des préoccupations des principaux acteurs de Parti pris. Ces derniers s'interrogeaient entre autres sur la sexualité des Canadiens français, sur leurs valeurs, leurs pratiques et leurs inhibitions. Il n'est pas sans intérêt de revenir sur ces

$$
+4
$$

4. Marcel RJoux, "Remarques sur le phénomène Parti pris", dans Index de Parti pris (1963-1968), Sherbrooke, CELEF, 1975, p. 6.

5. Voir Pierre MAHEU, Un parti pris révolutionnaire, Montréal, Editions Parti Pris, 1983; Paul Chamberland, Un parti pris anthropologique, Montréal, Editions Parti Pris, 1983; Jean-Marc PlOTTE, Un parti pris politique. Essais, Montréal, VLB éditeur, 1979; André J. BÉLANGER, Ruptures et constantes. Quatre idéologies du Québec en éclatement: La Relève, la JEC, Cité Libre, Parti Pris, Montréal, Hurtubise HMH, 1977; Pierrette BOUCHARD-SAINT-AMANT, "L'idéologie de la revue Parti pris: le nationalisme socialisme", Fernand DUMONT, Jean-Paul MONTMINY, Jean HAMELIN (dir.), Idéologies au Canada français, 1940-1976, Tome 1: la presse, la littérature, Québec, Les Presses de l'Université Laval, 1981, p. 215-355. Sur la vie des membres de Parti pris dans les années 1960, lire Malcolm REID, The Shouting Signpainters. A Literary and Political Account of Quebec Revolutionary Nationalism, Toronto, McClelland and Stewart, 1972. Pour replacer Parti pris dans la tradition des revues intellectuelles québécoises, lire Andrée FORTIN, Passage de la modernité. Les intellectuels québécois et leurs revues (1778-2004), Québec, Les Presses de l'Université Laval, 2006, ainsi qu'Ivan CAREL, "Les revues intellectuelles entre empêchement ec émancipation, 1950-1968n, chèse de doctorat, Département d'histoire, Université du Québec à Montréal, 2007. Pour comprendre l'influence de Marx sur la revue, lire Nicole LAURIN, "Genèse de la sociologie marxiste au Québec", Sociologie et sociétés, vol. 37, $n^{\circ}$ 2, automne 2005, p. 183-207.

6. Voir Robert MAJOR, Parti pris : idéologies et litterarure, Montréal, Hurtubise HMH, 1979; Max RoY, Parci pris et l'enjeu du récit, Québec, Cencre de recherche en littérature québécoise, Université Laval, 1987; Lise GaUVIN, Parti pris littéraire, Montréal, Presses de l'Université de Montréal, 1975; LouisBernard ROBITALLL, "L'idée de littérature dans Parti pris", mémoire de maîtrise, Département de langue et littérature françaises, Université McGill, 1972. 
discours et ce, d'autant plus que, contrairement à la plupart des chercheurs contemporains qui posent la question en termes psychologiques, les partipristes replaçaient la question de la sexualité québécoise dans un cadre sociologique et envisageaient sa solution de manière globale, une posture qui n'est pas sans rappeler, à peu près à la même époque, celle de Camille Laurin, qui parlait d'entreprendre une psychothérapie collective pour traiter le complexe d'infériorité du peuple québécois ${ }^{7}$. Les intellectuels de Parti pris voulaient, quant à eux, "créer un espace pour exercer [leur] sexualité, pour explorer un nouveau territoire imaginaire», ils voulaient "écrire avec [leurs] fantasmes, avec des images libres ${ }^{8}$ ". Cet érotisme allait permettre, à les en croire, à la fois l'épanouissement plein et entier de chaque individu et le libre déploiement de l'imaginaire national.

Résumons l'esprit de Parti pris en rappelant que cette publication se battait en termes polémiques pour la souveraineté du Québec, la laïcisation des institutions publiques et l'établissement d'un régime socialiste. Convaincus de la nécessité de s'engager, comme en Algérie ou à Cuba, en faveur de la décolonisation de leur société aux niveaux politique, économique, social et culturel, les membres fondateurs (André Brochu, Paul Chamberland, Pierre Maheu, André Major et Jean-Marc Piotte, âgés alors entre dix-neuf et vingt-quatre ans ${ }^{9}$ ) s'adonnaient à la lecture d'essais considérés sulfureux et garnissaient leurs bibliothèques des cuvres de Jean-Paul Sartre ${ }^{10}$, Albert Memmi, Franz Fanon, Jacques Berque, voire Karl Marx et Lénine ${ }^{11}$. Accompagnant la montée du terrorisme felquiste (dont ils voulaient constituer l'aile intellectuelle) et incarnant la frange radicale d'une Révolution tranquille en pleine ébullition politique et culturelle, les partipristes appliquaient à la société québécoise un schéma interprétatif qui puisait dans une littérature tiers-mondiste et socialiste alors en vogue dans les milieux

$$
+4
$$

7. Voir Pierre DUCHESNE, Jacques Parizeau, vol. 2: Le Baron, 1970-1985, Montréal, Québec Amérique, 2002, p. 493-502.

8. Nicole BROSSARD, "Ce que pouvait être, ici, une avant-garde", Voix et images, vol. $10, \mathrm{n}^{\circ} 2$, hiver 1985, p. $65-85$.

9. André Brochu est né en 1942, Paul Chamberland en 1939, Pierre Maheu en 1939, Jean-Marc Piotte en 1940 et André Major en 1942. Le comité de rédaction change considérablement avec le temps. Mentionnons seulement qu'André Brochu quitte dès avril 1964, remplacé par Laurent Girouard. En août 1965, le comité de rédaction accueille Gaston Miron, puis, en janvier 1967, Luc Racine et Raoul Duguay. 10. «La problématique sartrienne nous a passablement marqués. Sartre fut peut-être pour nous ce que Maritain avait été pour les rédacteurs de La Relèven (André BROCHU, "Écrire sur Parti pris", La Barre du jour, $\mathrm{n}^{\text {os }} 30-31$, hiver 1972 , p. 26)

11. Jean-Marc PIOTTE, "Parti pris: un printemps dans la vie intellectuelle du Québec", Possibles, vol. 30, $n^{\circ s}$ 3-4, été-automne 2006, p. 21-30; "Introduction", dans Un parti pris politique, op. cit., p. 9-28. Rappelons que Sartre, qui faisait du marxisme la philosophie véritable des temps modernes, a largement popularisé l'idéologie tiers-mondiste en France, en préfaçant les ouvrages de Senghor, Memmi, Fanon, 
gauchistes un peu partout dans le monde ${ }^{12}$. Cet élan protestataire se prétendait révolutionnaire, alors qu'en fait il ne faisait, en grande partie, que porter plus loin des tendances déjà fortement à l'œuvre dans la société québécoise. Les slogans laïcistes, indépendantistes et socialistes prolongeaient la déconfessionnalisation, l'autonomisme et le providentialisme de la Révolution tranquille. "L'impact culturel de Parti pris s'explique ainsi: elle n'a que radicalisé les idées de changements et de ruptures véhiculées par les divers courants qui se sont développés durant la Révolution tranquille ${ }^{13}$ "..$\AA$ lire les articles des partipristes, il est clair que leur conception de l'avant-garde trouvait sa légitimité dans un certain déblocage collectif, mais ils ne semblaient pas comprendre que ce déblocage emportait au même moment l'Amérique du Nord conservatrice et puritaine tout entière.

Ces remarques générales valent pour le cas particulier de la sexualité. Les partipristes ont écrit à un moment de profondes remises en question des valeurs nord-américaines, ainsi qu'en témoignent ne serait-ce que la filmographie de l'après-guerre, l'avènement de nouvelles méthodes de contraception et les progrès rapides de la médecine. Désormais, avec ou sans Parti pris, la pratique de l'amour libre sera considérée comme un des traits caractéristiques de la jeunesse, et, chez les enfants de l'après-guerre, la peur de paraître vieux jeu emportera bien des gênes et des réticences ${ }^{14}$. C'est donc dans ce contexte de bouleversement qui ébranlait les bases de la culture de l'après-guerre, tout en reconduisant par ailleurs certains archétypes masculinistes, qu'il faut relire les articles consacrés à la sexualité dans Parti pris. Leur originalité ne tient pas au fait qu'ils revendiquaient une plus grande liberté sexuelle mais à la critique qu'ils proposaient et au jugement qu'ils portaient sur la société québécoise. Tandis que la poésie publiée dans les Antilles, par exemple, mobilisait des symboles sexuels qui évoquaient la mère

$$
+4+
$$

Lumumba. Il n'est donc pas surprenant qu'après lui, ce soit Jacques Berque qui ait représenté, sans doure, l'influence la plus cardinale des partipristes. "On dir "Québerque libre". Parce que Berque est le père spirituel de Parti pris, enfin, d'une partie de Parti pris, disons. [...] D'ailleurs, Berque a des contacts très étroits encore [en 1969] avec certains membres de la revue (correspondance, etc.), et il suit de très près ce qui se passe ici, nous éclaire, nous aide et nous donne ce qu'il découvre-lui-même; on lui apporte, nous, des données" (Gérald GoDin, Ecrits et parlés, vol. I: Culture, Montréal, L'Hexagone, 1993, p. 191). Sur l'idéologie de la décolonisation au Québec, lire Pierre BEAUCAGE, rLe vent du sud. Les idées du TiersMonde et les marxistes québécois dans les années 1970 ", Revue canadienne de sociologie et d'anthropologie, vol. 37, no 1, 1990, p. 95-114 et Magali Deleuze et Papa DramE, "Les idées phares du processus de décolonisation et le Québec", Bulletin d'histoire politique, vol. 15, $n^{\circ} 1$, automne 2006, p. 109-129. 12. Voir Marthe-Francine TREMBLAY, "Culcure colonisée et ethnocentrisme. Québec 1950 à 1975: Cité Libre, Liberté, Maintenant, Parti Pris", mémoire de maîtrise, Département d'histoire, Université du Québec à Montréal, 1984.

13. Jean-Marc PIOTTE, "Introduction", dans Un parti pris politique, op. cit., p. 17.

14. Voir Jean-Philippe WARREN, Une douce anarchie. Les années 68 au Québec, Montréal, Boréal, 2008 (en particulier «Des valeurs contre-culcurelles», p. 120-131). 
et la terre nourricière (voir les recueils d'Aimé Césaire qui associaient fertilité et enfance ${ }^{15}$ ), la littérature révolutionnaire québécoise des années 1960 aura tendance à user d'un tout autre registre de correspondances métaphoriques. À une même époque, celle de la décolonisation, des nations animées par des préoccupations semblables produiront des réflexions singulières pour exprimer leurs malaises et leurs aspirations. Après un rappel des principaux thèmes que le lecteur retrouve dans les pages de Parti pris, nous verrons, en fin de parcours de cette analyse historique, comment la question de la sexualité s'alimentait à ce moment aux sources d'une tradition machiste qui reléguait les femmes au statut d'objet passif de la révolution à venir. Les ruptures avec les attentes de l'après-guerre ne devraient donc pas voiler les profondes continuités avec un modèle des rapports hommes-femmes qui perpétuait de nombreux stéréotypes sexistes.

\title{
IMPUISSANCE SEXUELLE ET IMPUISSANCE COLLECTIVE
}

\author{
The history of sexuality is national history ${ }^{16}$. \\ Steven MAYNARD, "The Maple Leaf (Gardens) Forever: \\ Sex, Canadian Historians and National History"
}

Telle que décrite par les partipristes, l'attitude des autorités traditionnelles envers le sexe était alors foncièrement et unanimement intolérante. Leurs témoignages insistaient sur le fait que la femme était tenue de jurer soumission à son mari, que les caresses entre époux étaient à peine tolérées, que l'acte sexuel était d'abord tourné vers la procréation ${ }^{17}$. Ces jeunes contestataires se désolaient de ce que la sexualité continuait d'être associée au vice et à la souillure corporelle. À les entendre, les relations sexuelles n'étaient jamais considérées en elles-mêmes mais seulement acceptées comme l'obligation de l'époux et de l'épouse, à qui il était demandé de sanctifier le mariage, ou comme le devoir du patriote, à qui il était demandé de faire sa part pour assurer la revanche des berceaux.

Il serait toutefois caricatural de s'en tenir à cette vision manichéenne de la Grande noirceur. Depuis au moins les années 1950, l’ancienne

$$
++
$$

15. Voir Jacqueline LEINER (dir.), Soleil éclaté: mélanges offerts à Almé Césaire à l'occasson de son soixantedixième anniversaire, Tübingen, G. Narr, 1985.

16. Steven MAYNARD, "The Maple Leaf (Gardens) Forever: Sex, Canadian Historians and National History", Joumal of Canadian Studies, vol. 36, $n^{\circ} 2,2001$, p. 72.

17. Jean-Marc PIOTTE, La Communauté perdue. Petites histoires des militantismes, Montréal, VLB éditeur, 1987 , p. $15-16$. 
morale catholique craquait sous les assauts d'une éthique plus ouverte aux expériences intimes des personnes. Loin de faire exception, la volonté exprimée par les partipristes de casser les tabous entourant la sexualité s'abreuvait à un contexte de remise en question de la famille traditionnelle à travers le continent. La société de consommation propageait des images et popularisait des attitudes considérées obscènes par les élites bien-pensantes, images et attitudes contre lesquelles ces élites multipliaient en vain les croisades de pureté. Élise Salaün écrit à ce sujet: "À deux ans de la Révolution tranquille, il est étonnant de constater à quel point les pratiques censoriales du clergé ne correspondent pas à la nouvelle réalité sociale du Québec d'après-guerre ${ }^{18}$ ". Les rédacteurs de Parti pris ne sauraient donc être assimilés à quelque génération spontanée, leurs premiers articles résonnant comme des coups de tonnerre dans une société québécoise autrement ingénue et paisible ${ }^{19}$. Dans les ouvrages consacrés au couple, malgré les réserves sans cesse exprimées face à l'impudeur des femmes, un certain érotisme faisait son apparition (les enfants devenant des enfants de l'amour et la bonne entente entre époux reposant sur l'attrait physique). Les idées personnalistes alors en vogue ne furent pas étrangères à cette évolution, sans mentionner des courants américains alimentés par l'enquête d'Alfred Kinsey et ses collaborateurs. En ce qui concerne la sexualité, comme en tant d'autres domaines, les Canadiens français connaissaient déjà à ce moment un bouleversement souterrain des mœurs que l'historien peut repérer dans les fréquentations entre garçons et filles, les lectures de journaux «jaunes" ou le taux de natalité.

Un certain contraste demeurait pourtant, en apparence du moins, entre le Québec et le reste de l'Amérique. La félicité domestique célébrée dans des publicités américaines, qui évoquaient les bungalows et de jeunes fiancées aux cheveux blonds, échappait encore en partie aux Canadiens français. Dans les années 1960, quand les collaborateurs de Parti pris comparaient leur rêve conjugal aux exploits d'un John Wayne, ils ne pouvaient que juger leur sexualité humiliée et humiliante. Interrogé sur l'absence de personnages masculins dans ses pièces, Michel Tremblay aurait répondu, dans une boutade que n'auraient pas désavouée les partipristes, que c'était parce qu'il n'y avait pas d'hommes au Québec ${ }^{20}$. En retour, les héroïnes aux

$$
++4
$$

18. Élise SALAÓN, "Erotisme littéraire et censure», op cit., p. 303.

19. Voir Diane GERVAIS, "Morale catholique et détresse conjugale au Québec. La réponse du service de régulation des naissances Seréna, 1955-1970", Revue d'histoire de l'Amérique franfaise, vol. 55, $n^{\circ} 2$, auromne 2001, p. 185-215.

20. Cité dans Robert SCHWARTZWALD, "La fédérastophobie, ou les lecrures agitées d'une révolution tranquille", Sociologie et soctetés, vol. 29, $\mathrm{n}^{\circ} 1$, printemps 1997, p. 133. 
tenues aguichantes et aux poses séductrices qui habitaient les romans signés par des auteurs de la mouvance de Parti pris sont souvent des étrangères. "Le héros du film [de Claude Jutra] est comme bien des Canadiens français de trente ans, cultivés et sensibles, à qui il faut systématiquement des femmes noires, jaunes ou rouges, en tous cas "étrangères" pour connaître des liaisons enivrantes ${ }^{21}$ ". Pour la génération de l'après-guerre, la redécouverte de l'Amérique, celle de Roy Rogers et de Hopalong Cassidy, participait en ce sens d'une volonté de démolir un Canada français efféminé et névrotique afin de bâtir sur ses ruines un Québec jeune, viril et droit. L'impuissance politique de la nation de langue française reflétait dans l'histoire une impuissance plus inavouable, plus personnelle, celle d'individus opprimés n'ayant pas encore "appris l'orgueil d'être hommes" 22 ".

Au moment où paraît le premier numéro de Parti pris, en octobre 1963, cela faisait déjà quelque temps que les psychologues avaient entrepris une lecture de la sexualité qui débordait la thérapie individuelle. Les problèmes sexuels leur apparaissaient autant personnels que sociaux ${ }^{23}$. Aux États-Unis, des spécialistes se penchaient, quoique davantage dans une perspective behavioriste ou fonctionnaliste, sur les déviances provoquées par le développement de la société américaine. Puisant à d'autres sources, les collaborateurs de Parti pris s'inscrivaient dans une tradition freudienne aux forts accents marxistes ${ }^{24}$. Pour eux, depuis la Conquête britannique, le système colonial canadien avait favorisé chez les individus de langue française une régression des valeurs et une infantilisation des mentalités. La psychologie des dominés s'en était trouvée compromise, ceux-ci souffrant de lourdes pathologies dans leur vie quotidienne ${ }^{25}$. Opprimé par des élites étrangères, le

$$
+4
$$

21. Denys ARCAND, "Cinéma et sexualité ", Parti pris, vol. 1, nos 9-10-11, été 1964, p. 96.

22. Pierres VALLIÈre, Negres blancs d'Amérique. Autobiographie précoce d'un "terroriste" québecois, Paris, François Maspero, 1969, p. 19. Dans Trou de mémoire, on peut lire: "Mon comportement sexuel est à l'image d'un comportement national frappé d'impuissance" (Hubert AQUIN, Montréal, Le Cercle du Livre de France, 1968, p. 112).

23. Voir Gascon DESJARDINS, L'amour en patience. La sexualité adolescente au Québec, 1940-1960, Québec, Les Presses de l'Université du Québec, 1995. Parti pris a publié un article qui résume les résultats d'une de ces études réalisées par des psychologues et des sociologues: Andrée BENOIST, "Valeurs culturelles et répression mentale" , Parti pris, vol. 1, nos 9-10-11, été 1964, p. 30-36. Benoist fait érat d'un taux anormalement élevé de dépression chez les Canadiens français.

24. Voir Jean-Marc P1OTTE, "Introduction", dans Un parti pris politique, op. cit., p. 12-13. Il est à noter que Herbert Marcuse n'eut qu'une influence diffuse et tardive: "Herbert Marcuse n'est devenu connu, hors des cercles philosophiques, que tout récemment" (Gilles DOSTALER et Luc RACINE, "Contre Marcuse. Essai sur la pensée idéologique dans les sociétés industrielles avancées", Socialisme $69, \mathbf{n}^{\circ} 19$, occobre-décembre 1969, p. 39-63). Wilhelm Reich n'est pas souvent cité dans les années 1960, mais sa thèse d'une répression et diversion de l'énergie vitale par les classes dominantes semble avoir connu une certaine popularité au sein des cercles intellectuels québécois.

25. Pierre LefebVRE, "Psychisme et valeurs nationales », Parti pris, vol. 1, nos 9-10-11, écé 1964, p. 16. 
peuple canadien-français se serait peu à peu réfugié dans des pratiques perverses compensatoires, tentant par des parades maladroites d'échapper au mal colonial. Les traits fondamentaux de son caractère - la honte, la peur et une troublante puérilité - auraient trouvé là leur source première:

En intériorisant les forces qui nous désintégraient - par lâcheté ou par impuissance - nous avons changé le ressentiment contre l'autre en culpabilité (haine de soi), transformé la révolte et le désir de liberté (instinct de vie) en soumission masochiste et en délire de persécution (instinct de mort). De par sa situation, chaque Canadien français est, au départ, un malade, de cette maladie qu'est le Québec ${ }^{26}$.

Chamberland n'était pas seul à considérer les effets du système colonial sur les structures sociales autant que sur la psyché collective. Nombreux étaient alors les intellectuels critiques qui croyaient que le Québec était atteint dans sa conscience collective autant que dans sa culture ou son économie.

En particulier, il leur semblait que la dépossession nationale provoquait des effets fâcheux et morbides sur les relations sexuelles. La défaite des Plaines d'Abraham avait signifié, à les entendre, la victoire historique de Thanatos sur Éros.

On a déjà noté, résumait Michel van Schendel, que le colonialisme s'accompagnait, là où il sévissait, de nombreuses formes de désorganisation sociale et de proscription mentale. On a noté le malaise, tantôt violent, tantôt apathique, qui s'emparait, devant l'amour, des éléments les plus éduqués des pays coloniaux, comme si l'amour devenait l'image insupportable non d'une union mais d'une scission profonde au coeur de leur existence ${ }^{27}$.

S'inscrivant dans l'optique de la décolonisation, les éditeurs de Parti pris trouvaient dans le sujet de la sexualité matière à revoir toujours le même problème de l'aliénation et de l'exploitation des Canadiens français. La libération sexuelle - vue, soulignons-le tout de suite, à travers un prisme fondamentalement masculiniste - représentait, aux yeux de ces utopistes, une facette essentielle d'une pleine et entière libération humaine: "Si cette

$$
+4
$$

26. Paul Chamberland, "De la damnation à la liberté", Parti pris, vol. 1, nos 9-10-11, été 1964, p. 67. 27. Michel VAN SCHENDEL, "L'amour dans la littérature canadienne-française", Fernand DUMONT et Jean-Charles FalaRdeAU (dir.), Littérature et societté canadiennes-françaises, Québec, Presses de l'Université Laval, 1964, p. 165. Van Schendel est aussi l'auteur de "La maladie infantile du Québec", Parti pris, vol. 1, n 6, mars 1964, p. 21-41. 
liberté recherchée doit être globalement sociale, religieuse et politique, elle doit être aussi, particulièrement, sexuelle; puisque toute existence libre et tocale exige une appréhension également libre et totale des réalités sexuelles ${ }^{28}$ ". Pour les jeunes partipristes, comme déjà pour les jeunes de $L a$ Releve $^{29}$, la censure qui frappait les relations sexuelles consacrait une aliénation impardonnable, dans la mesure où les individus se trouvaient coupés des jouissances physiques et de leurs sens. En ne pouvant, assuraient-ils, jamais parler de sexe, ni même de tendresse, ou alors en se trouvant à en parler très mal, d'une manière superficielle et ridicule, les Canadiens français perdaient contact avec leur propre corps et vivaient, pour ainsi dire, en dehors d'eux-mêmes, dans le confort bourgeois d'images proprettes et insignifiantes telles qu'une flopée de pédagogues en faisaient circuler à l'époque dans les collèges.

La ségrégation des sexes pendant la majeure partie de l'enfance et de l'adolescence rendait les relations entre garçons et filles difficiles. Étrangers les uns aux autres, ils entraient dans l'aventure du mariage sans préparation, presque avec effroi. Ayant grandi dans des sphères séparées, ils entretenaient les uns envers les autres une méfiance naturelle, faite à moitié de fascination coupable et à moitié de répulsion morale. Cette situation, plutôt commune dans le monde occidental, était renforcée dans la province, au dire des collaborateurs de Parti pris, par le caractère opprimé de la société canadiennefrançaise. Déjà, l'organisation de la cellule familiale avait de quoi susciter des comportements déviants. Incapable de se réaliser dans un monde politique ou économique contrôlé par les Anglais, la figure du père adoptait des traits avachis, avilis, toujours pitoyables face à la rayonnante figure maternelle. Pierre Vallières, dont les jeunes militants des années 1960 suivaient attentivement la carrière intellectuelle, a donné dans Nègres blancs d'Amérique une longue description autobiographique d'une famille où la mère castrait ses fils en exerçant, par le chantage de l'amour, une violence sournoise ${ }^{30}$. Il a eu

$$
++\div
$$

28. Denys ARCAND, "Cinéma et sexualité", op. cit., p. 90.

29. Lire, par exemple, les propos de Jean LE MOYNE dans Convergences (Montréal, HMH, 1961): "Maintenant le sexe mystérieux et rageur va s'emparer de nous et constituer le mal. [...] Jusqu'à la fin, jamais un mor d'explication sur la vocacion qui allait être celle de l'immense majorité: le mariage. La femme n'existait pas " ("L'atmosphère religieuse au Canada français", p. 63). La différence majeure entre La Relève er Parti pris, c'est que les intellectuels des années 1930 dénonçaient cette déficience morale au nom d'un idéal religieux censément plus "incarné" et plus "authentique" (voir la théologie maritale d'Herbert Doms). Leur révolte étair d'abord spirituelle. L'observation vaur pour le groupe assemblé autour de Cité libre.

30. Pierres VALLIÈrES, op. cit. L'ouvrage est dédié à la mémoire de son père . "A la maison, [mon père] était un vaincu. Il n'était pas le seul dans cette situacion. Plusieurs des amis de mon père avaient été vaincus par leur femme" (p. 86). Et encore: "Le capitalisme et la religion ont fabriqué en série des mères 
beau reconnaître plus tard avoir proposé une interprétation sexiste du passé canadien-français ${ }^{31}$, cette vision fut partagée par maints auteurs de sa génération ${ }^{32}$.

Il est évident que cette grille idéologique détermine fortement l'interprétation de l'histoire québécoise proposée dans les pages de la revue dirigée par Pierre Maheu et que la figure du père ne correspond pas unanimement à cette description dépressive d'époux ratés. Il n'y a pas eu que des papas Plouffe au Canada français. Le modèle unique de père déchu est une construction qui servait des fins politiques et polémiques ${ }^{33}$. Qu'à cela ne tienne. Dans un raccourci évocateur, qui reprenait sans le nommer un texte de Jacques Berque, Maheu affirmait que l'omniprésence de l'image de la mère castratrice était "la conséquence normale de la Conquête ${ }^{34}$ ". La domination des Anglais aurait enlevé aux pères canadiens-français les attributs ordinaires de la puissance et les mères, depuis ce temps, auraient détenu par défaut une autorité qu'ils auraient dû normalement assumer ${ }^{35}$. Que ce soit dans la sphère économique ou politique, les pères auraient été confinés au mépris, à l'abdication et au silence.

$$
+4
$$

comme la mienne... et rares sont les Québécois - du moins dans la classe ouvrière - qui n'ont pas été, à une certaine période de leur vie, asphyxiés par l'amour (?) d'une mère possessive" (p. 99).

31. Nicholas M. ReguSH, Pierre Vallieres. The Revolutionary Process in Quebec, New York, The Dial Press, 1973, p. 137.

32. Jacques GODBOUT confessait avoir écrit ses premiers textes "pour [son] père, au sens large du terme" ("Novembre 1971/Écrire", Le réformiste. Textes tranquilles, Montréal, Quinze, 1975, p. 157). Charles GAGNON, né en 1939, reconnaissaic se bactre pour l'honneur perdu de son père (Feu sur l'Amérique, Ecrits politiques, volume I, 1966-1972, Moncréal, Lux, 2006). D'à peu près dix ans l'aîné de la génération de Parti pris, Fernard Dumont (1927-1997) élèvera le silence des pères au statut de mythe fondateur de la modernité québécoise, tentant de réchapper le mutisme paternel dans une parole neuve qui charrie leurs sourdes frustrations et leurs espoirs innommés (Voir Jean-Philippe WARREN, Un supplément d'àme. Les intentions primordiales de Fernand Dumont (1947-1970), Sainte-Foy, Presses de l'Université Laval, 1998). Gilles Gagné a offert une interprétation sociologique de cet état de fait (Gilles GAGNé (dir.), Le Canada français. Son temps, sa nature, son héritage, Québec, Nota Bene, 2006, p. 159-160). Il est aussi fort probable qu'une partie de ce discours découle du mépris de soi intériorisé par les Canadiens français à force de se faire accuser de lâcheré et d'"unmanliness" par des Canadiens anglais qui, depuis les Première et Seconde Guerres mondiales, concevaient la virilité en des termes militaires et ne pouvaient comprendre que de vrais hommes aienr cherché à déserter ou à s'opposer à la conscription. Lire à ce sujet Jeffrey VACANTE, «Evolving Racial Identity and the Consolidation of Men's Authority in Early Twentieth-Century Québec", The Canadian Historical Review, vol. 88, $n^{\circ} 3$, septembre 2007, p. 413-438. Sur l'histoire de la virilité en Occident, lire Georges L. MOSE, L'image de l'homme. L'invention de la virilité moderne, Paris, Agora, 1996.

33. Lire, par exemple, la monographie, parue au même moment, de Philippe GARIGUE, La vie familiale des Canadiens français, Montréal, Presses de l'Universiré de Montréal, 1962. Pour une étude plus concemporaine, lire Daniel DAGENAIS, "Le type sociologique de la famille canadienne-française ", dans $L a$ fin de la famille moderne, Québec, Presses de l'Université Laval, 2000, p. 177-193.

34. Pierre MAHEU, "L'CEdipe colonial ", Parti pris, vol. 1, nos 9-10-11, été 1964, p. 36. Voir Jacques BERQUE, "L'CEdipe colonial $"$, dans Dépossession du monde, Paris, Seuil, 1964, p. 39-51. Il est possible que Berque ait aussi évoqué cette idée dans les cours qu'il donna au Département d'anthropologie de l'Université de Montréal en 1962.

35. André BENOIST, "Valeurs culturelles et dépression mentale", op. cit., p. 34. 
Alors que l'Église romaine aurait pu incarner un lieu où les hommes auraient exercé une réelle autorité (cette institution patriarcale distillant depuis des siècles un discours méprisant envers le "sexe faible" et refusant aux femmes toute position dominante), la vérité, pour les partipristes, c'était qu'il n'en était rien. Même placés très haut dans la hiérarchie épiscopale, les mâles qui accédaient à la prêtrise étaient des hommes castrés, soumis à l'autorité de leur mère, l'Église ${ }^{36}$. Les bons pères en robe illustraient, par leur dévotion à la Vierge Marie, l'étendue de leur humiliation. La pensée républicaine des Patriotes, dans un sursaut qui n'eut pas de suite, avait bien tenté de faire la part belle aux hommes ${ }^{37}$, à qui étaient confiées les responsabilités viriles de la citoyenneté (leurs épouses étant refoulées dans les cuisines et les pouponnières), mais elle fut écrasée par une idéologie ultramontaine qui, jouant sur le même stéréotype, honorait pour sa part la reine du foyer et la gardienne des traditions sur qui les clercs projetaient leurs espoirs de régénérescence de la race canadienne-française ${ }^{38}$. C'est ainsi qu'historiquement, le culte bourgeois du bonheur domestique allait se conjuguer au projet cléricaliste et nationaliste de la deuxième moitié du $\mathrm{XIX}^{e}$ siècle, culte dans lequel les femmes, pures, dévotes et soumises, devaient tenir le premier rôle (comme en témoigne, à un autre niveau, l'essor de la dévotion mariale) en assurant la survie du peuple canadien-français par la revanche des berceaux et par la transmission de la culture ${ }^{39}$.

Du côté des travailleurs, le stéréotype répandu dans les cercles de gauche était celui du porteur d'eau et du locataire, en bref, de l'homme impuissant mis en scène dans les chansons de Gilles Vigneault (Ti-Cul Lachance) ou dans les monologues d'Yvon Deschamps ("Les unions qu'ossa donne?"). Il serait fastidieux d'accumuler les témoignages de cette abnégation publiés dans les années 1960. Le "silence des pères" (qui servira de contraste à "l'âge de la parole") confirmait une coupable résignation qui se traduisait, dans une sorte de rationalisation psychanalytique, par l'expression "né pour un p'tit pain». Chez les agriculteurs, les images

$$
+4
$$

36. Voir Jean-François ROUSSEL, "Roman Cathölic Religious Discourses about Manhood", Journal of Men's Studies, vol. 11, $\mathrm{n}^{\circ} 2$, hiver 2003, p. 145-155.

37. Voir Allan Greer, "The Queen is a Whore! ", dans The Patriots and the People. The Rebellion of 1837 in Rural Lower Canada, Toronco, University of Toronto Press, 1993, p. 189-218.

38. Voir Christine HUDON, «Des dames chrétiennes. La spiritualité des catholiques québécoises au XIX" siècle ", Revue d'histoure de l'Amérique française, vol. 49, $\mathrm{n}^{\circ}$ 2, automne 1995, p. 169-194.

39. "La Canadienne restait à la maison. Son sexe fort ramenait les nomades. C'est elle qui a fixé le pays. Aucour de ses jupes" (Jacques FERRON, "La neige flambe", Parti pris, vol. 1, n 6, mars 1964, p. 60). Ferron s'était vu confier une chronique dans Parti pris dès les premiers numéros. 
maternelles étaient encore plus fortes, à l'évidence, le labour des champs se confondant à une union sacrée avec la terre maternelle.

Enfin, du côté politique, le gouvernement central représentait l'Anglais, l'étranger, le dominateur, et ne pouvait symboliser d'aucune façon la virilité canadienne-française. Au contraire, Pierre Maheu allait jusqu'à affirmer que, dans leurs relations avec Ottawa, les Canadiens français s'étaient construit un imaginaire politique régressif: depuis que la mère patrie avait été violentée par le roi britannique avant d'être abandonnée, comme une vulgaire fille du Roi, par son père, le roi de France, les Canadiens français n'en finissaient pas de revivre cette humiliation originelle, ce que confirmaient les métaphores conjugales régulièrement utilisées pour décrire les relations fédérales-provinciales ${ }^{40}$. Gérald Godin, dans une critique de Papa Boss, de Jacques Ferron, n'écrivait-il pas:

Le véritable état du Québec depuis 200 ans apparâit à mon avis dans ce thème de la femme fourrée sous de fausses représentations. Ainsi, le Québec croit-il constituer un couple normalement constitué avec Ottawa, alors qu'il n'est au fond que l'enculé de la farce, le bardache de l'histoire, l'être dont le sexe lui échappe au moment où il croit enfin pouvoir aimer ou être aimét ${ }^{41}$.

Du côté provincial, ce n'était guère mieux, puisque le chef d'État par excellence de la Grande noirceur était Maurice Duplessis, un homme «marié à sa province", dont le célibat ressemblait à celui des prêtres. D'ailleurs, la société canadienne-française était conçue comme une grande famille, où l'État provincial assurait des fonctions "maternelles", telles le secours aux indigents et l'administration des bonnes œuvres. D'un certain point de vue, la société canadienne de langue française aurait pu être jugée patriarcale, puisqu'elle était administrée, au fond, par des hommes politiques ${ }^{42}$, seulement cette interprétation aurait oublié que "l'univers d'affectivité" que l'État mettait en place concédait beaucoup aux fonctions associées à la mère

$++4$

40. «Dans l'ensemble, la perception de la confédération en termes de coexistence entre deux nations, semble figurer une liaison vénérienne rendue au paroxysme de l'écœurement, quand ce n'est pas l'image même d'un mariage chrétien, indissoluble et gâché, entre un poisson et un bélier. La confédération peut donc être saisie rhétoriquement selon les diverses catégories des "chaînes" de l'amour " (Hubert AQUIN, "Le corps mystique", Parti prts, vol. 1, n 5, février 1964, p. 30). Aquin relevait les thèmes du mariage forcé, de la femme frigide, du divorce à l'italienne, de l'epouse bafouée ("Ottawa viole notre autonomie" - Jean Lesage), de la belle-mère et des querelles de couple. Lire aussi Pierre LefEBVRE, "Les 32 positions du fédéralisme coopératif ou le kâmasoûtra [sic] de l'hon. Lamoncagne ", Parti pris, vol. 1, nos 9 10-11, été 1964, p. 168-173.

41. Gérald GodIN, "Papa boss", de Jacques Ferron", Parti Pris, vol. 3, n 9, avril 1966, p. 1.

42. Voir Gilles BOURQUE et Jules DUCHASTEL, La societé liberale duplessiste, Montréal, Boréal, 1994. 
dans la société traditionnelle, comme celles de s'occuper des vieillards, des invalides et de la jeunesse. Qui plus est, la famille, cellule de base de l'ordre social, assurait par l'éducation et la procréation la tâche primordiale entre toutes: la reproduction nationale, dans tous les sens de l'expression ${ }^{43}$.

Le citoyen était infantilisé dans sa relation au pouvoir politique, comme l'ouvrier l'était dans sa relation au pouvoir économique et le croyant dans sa relation à Dieu. Le vrai pouvoir, le pouvoir souverain, lui échappait. Dépossédé de ses institutions politiques, culturelles et économiques propres, il vivait en famille, la cuisine devenant le lieu privilégié de la socialité, un espace privé où les femmes en menaient large. Le Canadien français disparaissait "devant la toute puissance des mères ${ }^{44}$ ".

Ainsi résumée la thèse formulée dans Parti pris, il est facile de concevoir pourquoi, pour les intellectuels adhérant à ce courant de pensée, l'immaturité des Canadiens français ne pourrait être corrigée que par un vigoureux redressement socialiste, laïciste et indépendantiste, la fin du règne des Anglais dans les affaires économiques, du prêtre dans les affaires spirituelles et du gouvernement fédéral dans les affaires provinciales signifiant, du même coup, l'accession des Canadiens français au statut d'homme à part entière et la fin des "papas-patrons", des "papas boss", des "papas merde 45 ", des "Rois-nègres». La détresse des mâles allait plus loin encore, puisque, n'ayant pas de patrie, ils se seraient soi-disant sentis incapables d'avoir des enfants et d'assumer les responsabilités de la paternité. Pères manqués, fils manquants, aurait-on pu dire en lisant la prose idéologique des années 1960. "N'ayant pas eu de père, je n'ai pas eu d'enfant ${ }^{46}$." Tant que les fils ne se seraient pas faits les "sages-hommes" d'un pays, d'une patrie, d'une terre des pères, c'est-à-dire tant qu'ils ne se seraient pas faits les patriotes d'un territoire politique, public, et non plus les serviteurs d'un espace familial et privé, ils demeureraient enfermés dans la mère-patrie.

Au début des années 1960 , les Canadiens français projetaient encore sur une mère par procuration, l'Église catholique ou la langue française par exemple, leur fantasme de réconciliation intra-utérine. Aquin

$$
++4
$$

43. Voir Jean-Philippe WARREN, L'engagement sociologique. La tradition sociologique du Québec francophone, Montréal, Boréal, 2003. Theda SKOCPOL a quant à elle parlé au sujet des Étars-Unis d'un "maternalist welfare state" (Protecting Soldiers and Mothers: The Political Origins of Social Policy in the United States, Cambridge, Harvard University Press, 1992).

44. Denys ARCAND, "Cinéma et sexualités, op. cit., p. 92.

45. Serge Grenier, " $\hat{A}$ bas les papas. Petit conte pour enfants vulgaires", Parti pris, vol. $1, \mathrm{n}^{\circ} 8$, mai 1964, p. 62.

46. Gérald GoDIN, "Le Québec possible", dans Jean ROYER, Pays intimes. Entretiens, 1966-1976, Montréal, Leméac, 1976, p. 180. 
associait ainsi la défense de la langue française à un retour au stade oral, régression qu'il voyair ni plus ni moins comme une "plongée dangereuse dans un passé national tout récent mais refoulé quand la langue résumait, par la verbigération et les accès d'écholalie, le vouloir-vivre national de l'épouse sous-douée ${ }^{47}$ ". Quand ils ne vivaient pas de fantasmes, les Canadiens français fuyaient leur univers débilitant dans de pitoyables refuges. Par exemple, l'homme émasculé s'exilait dans les tavernes, où, soutenaient les partipristes, il noyait son malaise dans l'alcool, à l'abri du regard castrateur des femmes:

La taverne est le lieu où ni les femmes ni la morale ne sont admises; on y boit avec de grands gestes, on y entre avec une démarche virile, on y gueule, on y est libre des conventions et de la banalité quotidienne; mais que cette liberté est triste, qui se réduit à une fuite, et cette virilité honteuse, qui ne s'affirme qu'en l'absence des femmes ${ }^{48}$.

Dans ces établissements ségrégués, "refuge "viril" où l'exclusion des femmes offre une incarnation pratique au dégoût [...] à l'égard d'une société "féminisée" 49 ", les Canadiens français se faisaient un petit royaume où leur révolte n'allait pas plus loin que des beuveries sauvages et des déclarations molles d'ivrognes. Quand, dégrisés, ils revenaient a la maison, ils trouvaient devant eux le même pouvoir enveloppant et inhibiteur qu'ils ne savaient fuir. D'ailleurs, dans le joual de l'époque, n'appelait-on pas les tavernes des "biberons" ? Ne buvait-on pas sa bière "tablette" dans des bouteilles qui ressemblaient à des tétons (avant qu'elles n'adoptent une forme phallique dans les années 1980)? Les tavernes permettaient aux Canadiens français de se réconcilier avec eux-mêmes par la régression vers l'enfance beaucoup plus que par l'affirmation hardie de leur maturité. Quant aux parades de la SaintJean-Baptiste, à l'exhibitionnisme des hommes forts ou aux parties de hockey, ils offraient des exutoires tout aussi dérisoires.

Le Canada français aurait pu sembler une société matriarcale, les pères n'occupant aucune place dans l'ordre viril de la politique ou de l'économie, si ce n'était que les mères, confinées aux fourneaux, étaient elles aussi sacrifiées sur l'autel de la morale. La sainte Mère l'Église ne leur laissait pas

$$
+4
$$

47. Hubert AQUIN, "Le corps mystique», op. cit., p. 33.

48. Pierre MAHEU, "L'Edipe colonial", op. cit., p. 24. Voir Anouk BÉLANGER et Lisa SUMNER, "De la Taverne Joe Beef à l'Hypertaverne Edgar. La taverne comme expression populaire du Montréal industriel en transformation ", Globe, Retue internationale d'études québécoises, vol. 9, n², 2006, p. 27-48.

49. Paul Chamberland, "De la damnation à la liberte", op. cit., p. 77. 
davantage de rôle puissant et concret, mais, bien au contraire, en les sanctifiant dans leur rôle de parturientes, elle leur rendait un culte exalté au seul niveau du mythe. Pour le reste de leur existence, les mères vaquaient aux occupations les plus éreintantes et les plus prosaïques (repassage, lessive, ménage). On exigeait d'elles une vie de renonciations. Pendant une bonne partie de leur vie, les garçons avaient appris à considérer les filles comme des occasions de pécher ou à ne voir en elles que la future mère de leurs enfants. Lorsqu'ils ne les traitaient pas en putains, ils les abordaient froidement dans leur rôle materne ${ }^{50}$. Une fois mariés, les jeunes époux s'appelaient du nom de leur fonction sociale ("pôpa " et "môman ${ }^{51}$ ") même lorsqu'ils n'avaient pas d'enfants.

La magie finit toujours par opérer, tout Québécois finit par épouser sa mère; l'homme d'ici est impuissant ou hanté par l'impuissance parce qu'il est le fils de sa femme, et la femme, dans la mesure où elle refuse toute rencontre authentique avec la masculinité en châtrant ses fils et son époux, est elle-même abandonnée à la frigidité: je suis persuadé qu'il n'y a qu'une faible proportion de nos mères qui aient éprouvé un orgasme ${ }^{52}$.

Les époux s'infantilisaient mutuellement en consumant leur union, et finissaient par nier leur désir charnel par la réification de leurs rôles reproducteurs.

Le rapport à la chair était si perverti dans la province, avançaient les partipristes, qu'il ne trouvait à s'exprimer que dans des aberrations : "L'inceste et l'inversion sont les modalités privilégiées de la passion au Canada français - autant dans la littérature féminine que masculine ${ }^{53}$ ". Cette inversion et cet inceste découlaient ensemble d'un refoulement pathologique des pulsions naturelles. En premier lieu, incapables d'exprimer publiquement leur amour ou leur désir aux personnes de l'autre sexe, les Canadiens français n'auraient eu comme lieux de contact que les dortoirs des collèges ou la famille. Le pensionnat et le foyer devenaient des endroits où assouvir de manière odieuse et perverse une sexualité à laquelle même les couples ne pouvaient succomber. Cet inceste allait jusqu'à s'exprimer symboliquement entre époux : "Il fallait se conduire avec les jeunes filles

$$
+4
$$

50. Voir Gaston DESJARDINS, op. cit.

51. La série télévisée La petite vie a repris ce mocif sur un mode parodique dans les années 1990 (voir Michèle NeVERT, La perite vie ou les entrailles d'un peuple, Montréal, XYZ, 2000).

52. Pierre MAHEU, "L'CEdipe colonial", op. cit., p. 26.

53. André BROCHU, "Amadou - ou: les cercles du mal", Parti pris, vol. 1, $n^{\circ} 4$, janvier 1964, p. 58. 
comme si elles étaient nos mères ${ }^{54}$ ". Le fils finissait par épouser sa "môman", et si la fille faisait de même avec son "pôpa", cette relation incestueuse semblait moins humiliante pour elle, d'un point de vue freudien, car elle dévoilair sa puissance érogène. En second lieu, la renonciation sexuelle, qui aurait pu parvenir à sublimer la sexualité dans des formes artistiques ou intellectuelles, prenait la forme bien catholique d'une renonciation au monde. Pour Denys Arcand, le film Aurore offrait un condensé exceptionnel de cette aliénation canadienne-française : la petite Aurore, bafouée et battue, trouvait un plaisir morbide à éprouver le martyre ${ }^{55}$. Au dire d'Arcand, cette satisfaction maladive était en partie la conséquence d'un refoulement sexuel issu d'une morale rigoriste catholique qui forçait la jeune fille à trouver un exutoire à des passions dites immorales dans une souffrance rédemptrice. Elle découlait également, au niveau global, d'un système colonial qui conduisait à l'autodénigrement. Portée par un jansénisme religieux et l'intériorisation du mépris de l'Autre, la culpabilité d'être soi nourrissait chez les Canadiens français un comportement masochiste. La nation, considérée comme une victime innocente de puissances étrangères (les Anglais, les Juifs, les Francsmaçons) prenait goût à son malheur, et le tournait, par compensation catholique et nationaliste, en vocation messianique. Inutile d'insister sur le fait que ce masochisme national renforçait l'impuissance (politique et sexuelle) collective. N'ayant jamais pu jouir, les Canadiens français célébraient leur continence et transformaient leur humiliation en vertu catholique.

\section{AMOUR, SEXISME ET MACHISME}

Je ne crois pas à un révolutionnaire qui négligerait de bien faire l'amour ${ }^{56}$.

Paul CHAMBERLAND, Un parti pris anthropologique

Ici commence un nouvel itinéraire, celui de la chair encore vierge qui rêve d'un Graal érotique, première forme d'une repossession du monde, premier symptôme littéraire de la décolonisation approchante ${ }^{57}$.

Michel VAN SCHENDEL, "L'amour dans la littétature canadienne-française"

$$
+\div
$$

54. Jean-Marc PIOTTE, La communauté perdue, op. cit., p. 15-16.

55. Voir Denys ARCAND, "Cinéma et sexualité, op. cit.

56. Paul CHAMBerland, Un parti pris anthropologique, op. cit, p. 220. Chamberland a publié plus tard des poèmes tendancieusernent érotiques dans Le Prince de sexamour (Montréal, L'Hexagone, 1976). Notons que les Éditions Parti Pris ont fait paraître, en 1973, Apprenons à faire l'amour de Loraine ARNODIN. 57. Michel VAN SCHENDEL, «L'amour dans la littérature canadienne-française", op. cit., p. 164. 
Face à une autorité qui ne se dressait pas devant eux mais menaçait de les "avaler", de les "bouffer", de les "engloutir dans les sables mouvants de la Mère ${ }^{58}$ ", les fils ne pouvaient rêver d'accomplir le suprême fantasme freudien. L' "impossibilité d'atteindre une "sexualité quotidienne" " découlait d'un "complexe d'Édipe non résolu", faute pour eux de pouvoir s'opposer au père ${ }^{59}$. Leur père était mort, assassiné par un faux père, un père illégitime, qui avait fait de tous ses enfants des bâtards et continuait d'abuser impunément de la vraie mère, la nation, en s'associant avec une marâtre, l'Église. En outre, ils avaient, de fait, épousé leur mère, mais une mère sans cesse violée et abusée, devenue à la fois une putain et une victime politiques, un fait brutalement illustré par l'agression incessante de la langue. Le dénouement du drame freudien passait donc par une inversion du supposé mythe primordial de l'humanité. Il fallait, pour les partipristes, divorcer de leur mère et réhabiliter le pouvoir phallique du père en l'arrachant à la mort symbolique qui le condamnait à l'insignifiance dans le régime colonial. La sexualité des Canadiens français s'en trouvait, on en conviendra sans peine, passablement compliquée.

Adoptant un comportement machiste, dont nous analyserons les ramifications plus loin, les partipristes avaient dans un premier temps tenté de répondre au viol par le viol: "Mon comportement sexuel est à l'image d'un comportement national frappé d'impuissance: plus ça va, plus je sens bien que je veux violer. Faire l'amour normalement ne m'intéresse plus vraiment $[. .$.$] . Fatigué, je rêve à la plénitude du vio { }^{60}{ }^{\text {}}$. Cette violence sauvage n'étant pas suffisante, il fallait dépasser ce stade de révolte primaire afin de reprendre possession de "notre être-père». La solution passait, d'une part, par le meurtre du père usurpateur (auquel la violence felquiste n'est pas étrangère), à savoir le pouvoir colonial, et, d'autre part, par une réconciliation avec la femme charnelle et aimante. Pour Pierre Maheu, cette acceptation de l'être-charnel, cette réconciliation avec la femme comme épouse et comme amante instaurerait dans le même geste une praxis révolutionnaire. Il existe en ce sens une relation directe, dans le discours révolutionnaire de

$$
\div+\div
$$

58. Pierre MAHEU, "L'G'Edipe colonial", op. cit., p. 24-25. Il est intéressant que Maheu utilise le verbe avaler, tout comme Réjean DUCHARME dans L'avalee des avales: "Tout m'avale! [dit Bérénice dans le passage qui ouvre le roman]. [...] Je suis avalée [...] par le visage trop beau de ma mère " (Paris, Gallimard, 1966 , p. 7). Suivant l'hyporhese formulée par les parcipristes, la fixation sur l'enfance et la récurrence du thème de l'inceste dans l'œuvre de Ducharme accuseraient chez cet auteur une régression dans le complexe d'CEdipe.

59. Denys ARCAND, "Cinéma et sexualité», op. cit., p. 96.

60. Hubert AQUIN, Trou de mémoire, op. cit., p. 112. 
l'époque, entre la réalisation de la souveraineté nationale et la libération sexuelle:

L'homme, complet et sexué, s'assumant en toute liberté, en toute lucidité, et avec cette "sérénité crispée", l'homme québécois en mots dit par Ouellette, c'est décidément très nouveau, très fort et très beau. [...] Me comprendra-t-on si je dis que tout cela me donne la certitude de la conquête prochaine de l'indépendance du Québec ${ }^{61}$ ?

Il fallait naître d'un coup à la vie, à la sexualité et à la nation.

Dans cette morale de l'incarnation, le contact avec la chair constituait un passage obligé. En se libérant de la mère et en faisant de la femme une amante et une épouse, l'homme canadien-français pourrait "descendre aux enfers de l'aliénation coloniale» et "y vaincre nos monstres maternels et castrateurs ${ }^{62}$ ". La femme, toujours perçue comme un objet, représentait moins, ici, l'occasion d'une aventure que la promesse d'une réconciliation ${ }^{63}$. Cette "marche à l'amour" s'effectuait non sans ferveur. C'est que cette recherche de communion humaine promettait de transformer l'accouplement de deux êtres en salut personnel et en victoire nationale. C'est le sens de la critique formulée par Denys Arcand à l'égard du film de Claude Jutra, $A$ tout prendre. Arcand reprochait au cinéaste de n'avoir pas saisi l'occasion de son film pour présenter aux spectateurs québécois une liaison hétérosexuelle normale. Il avouait languir après le jour où

les cinéastes auront oublié leur maman pour déshabiller sereinement leur voisine qui s'appellera Yvette Tremblay ou Yolande Beauchemin, en plein soleil et avec une grande angulaire bien en foyer sur la caméra. $[\hat{A}]$ partir de ce moment-là, nous pourrons envisager comme Jean Renoir un cinéma libre en même temps que férocement national ${ }^{64}$.

Pierre Maheu s'en disait convaincu : "L'apparition dans notre littérature d'un érotisme sain et heureux témoigne d'une transformation

$$
+4
$$

61. Pierre MAHEU, "Un tabou vaincu ", Parti pris, vol. $5, \pi^{\circ} 7,1968$, p. $50-51$.

62. Pierre MAHEU, "L'CEdipe colonial ", op. cit., p. 29. Sur le thème de l'amour et de la sexualité dans le roman de la première moitié des années 1960, lire Maurice ARGUIN, Le roman québécois de 1944 à 1965 , Montréal, L'Hexagone, 1989, p. 244-245.

63. Voir Paul Chamberland, L'inavouable, Montréal, Éditions Parti Pris, 1967. Notons au passage que cet appel à l'érotisme n'étair pas nouveau dans la poésie québécoise, bien que les partipristes se prétendaient les premiers à aborder cette thématique de front.

64. Denys ARCAND, "Cinéma et sexualitén, op. cit., p. 97. 
profonde du Québec, d'une victoire majeure ${ }^{65}$ „. Il ne s'agissait certes pas pour lui de se réjouir de la prolifération des revues pornographiques (ce qu'il appelait le "déferlement d'un érotisme pour voyeurs et onanistes") mais de célébrer une démarche qui assumait pleinement la sexualité en la replaçant dans le flux vital des personnes. Le joual, par exemple, était réhabilité parce qu'il apparaissait comme une langue sale, une langue "cochonne», la langue des "vrais hommes", des ouvriers, des gars costauds et endurcis, bien differente du beau langage en cul-de-poule des "tapettes" et des "fifis" de RadioCanada ${ }^{66}$. Depuis au moins le tournant du $\mathrm{XX}^{\mathrm{e}}$ siècle, le fait de bien parler français était considéré au Québec comme un comportement efféminé: le langage châtié, c'était celui des "eunuques". Le joual, signe de l'humiliation des Canadiens français, sera paradoxalement repris par les partipristes pour bien marquer leur virilité reconquise, le défi lancé aux intellectuels du sein même de l'intelligentsia. En expurgeant le langage de ses interdits puritains, en ouvrant les vannes du blasphème, du scatologique, des "gros mots" et de l'érotique, ils signifiaient désormais avec force le refus de plier devant les pouvoirs, de s'avouer soumis, vaincus, dociles. L'éducation "émasculée" (dixit Godbout) des collèges classiques serait remplacée par une culture vivante, tonifiante, musclée et hardie, qui n'aurait plus aucune ressemblance avec les incantations mièvres de la morale de jadis. La langue maternelle prendrait les accents d'une langue paternelle, dans le même mouvement où elle s'éloignerait d'une France jugée trop efféminée (les Français étant accusés d'être tous plus ou moins pédérastes) et se rapprocherait par ses tournures et ses anglicismes d'une Amérique conquérante.

En rejetant les interdits, en libérant leurs pulsions organiques, les Canadiens français instaureraient non seulement une relation plus épanouissante avec l'autre sexe mais hâteraient leur libération nationale : "Jacques Benoît dit que les Québécois commencent à s'aimer. Et quand un peuple humilié se met à aimer, c'est qu'il est sur le chemin de la libération ${ }^{67}$." La solidarité révolutionnaire prenait au Québec des couleurs amoureuses.

$$
+4+
$$

65. Pierre MAHEU, "Un tabou vaincu", op. cit., p. 65. Hubert Aquin lui donnait raison: "La révolte des fils, des castrés, des invertis, des amoureux qui finissent dans le clergé; cecte révolte qui révèle assez bien l'impuissance qu'elle veut masquet, certe révolte qui [...] est rudement présente d'un bout à l'autre de notre histoire littéraire, est vraiment démodée. Elle se porte mal de nos jours. Et ces nouveaux écrivains, je l'avoue, me font oublier leurs prédécesseurs, glorieux et incompris, qui n'ont pas fini de regarder de bien haut un public qu'ils ennuient. De plus, cette littérarure nouvelle me rassure sérieusement quant à l'orientation sexuelle globale de notre pays où, si l'on avait continué de sacraliser les ambivalences et les castrés, je me serais senci de trop" (Hubert AQUIN, "Commentaires. 1", Fernand DUMONT et JeanCharles Falardeau [dir.], op. cit., p. 192 193).

66. Gérald GODIN, "Le joual et nous", Parti pris, vol. 2, n 5, janvier 1965, p. 18-19.

67. André MAJOR, "Un long détour", La Barre du jour, n ${ }^{\circ 5} 31-32$, hiver 1972, p. 46. 
Dans un tel contexte, il était à prévoir que les écrivains de la lignée de Parti pris en viennent à confondre, dans leurs écrits, femme et terre promise ${ }^{68}$. A plusieurs occasions, ils n'hésitèrent pas à projeter sur les femmes (toujours ravalées au statut d'êtres passifs et instrumentalisés) leur vision nationale. Le thème de la reconquête de la "femme-pays" revient sans cesse dans les pages de la revue. C'est une fois parvenus sur les "collines de mon pays ma femme ma patrie étendue au flanc de l'Amérique ${ }^{69}$ " que les militants s'imaginaient pouvoir renaître enfin à la vie. Reprenant les symboles de la religion catholique pour mieux les profaner, Raoul Duguay faisait de l'amour avec une femme la métaphore de l'enfantement d'un pays libre.

D'amour suprême d'A et ton sexe est un tabernacle où chrisser l'âme de ma verge et fleurir dans ton ventre le nouveau Dieu-homme du Québec [...] et ton ventre est un calvaire où mourir de joie en croix sur toi pour sauver le Québec [...]

Et mon sexe est une hostie qui vient fondre dans ton vagin et répandre sa sainte crème pour baptiser ton corps de beauté et ton corps est un sanctuaire où je tiens ma verge allumé comme un flambeau de liberté dans les rues, ruelles du Québec e ${ }^{70}$.

Ce qu'il faut s'empresser d'ajouter, c'est que cette réconciliation des sexes passait, dans les pages de Parti pris, par une vision très masculine. Malgré les nobles discours proclamant venu le règne de l'égalité, la pureté révolutionnaire était souvent acquise, en définitive, aux dépens des femmes. Malcolm Reid avait raison d'écrire: "La pro-sexualité de Parti pris était quelque chose d'incomplet, à qui [sic] manquait une dose de Women's $L^{2} b^{71}$ ". Publiée à une époque où les préoccupations féministes n’avaient pas encore

$$
+\div
$$

68. Voir Jacques PELLETIER, Lecture politique du roman québécois contemporain, Montréal, Universicé du Québec à Moncréal, 1984, p. 52-53.

69. Jacques BRaUlT, "Suite fraternelle", Parti pris, vol. 1, $n^{\circ} 2$, novembre 1963 , p. 40.

70. Raoul Duguay, "La poésie rebelle", Parti pris, vol. $5, n^{\circ} 6$, mars 1968 , p. 53 .

71. Malcolm REID, "Parti pris", La Barre du jour, nos 31-32, hiver 1972, p. 109. 
réussi à occuper le devant de la scène intellectuelle québécoise, la revue était animée par des hommes, pour des hommes. Ces jeunes militants de gauche cédaient sans toujours s'en apercevoir au préjugé selon lequel les femmes auraient été soumises et passives, alors que, par opposition, leurs confrères de lutte auraient été virils et moralement supérieurs ${ }^{72}$ : "Nous ne voulons pas nous laisser posséder par les mous, les tendres. [...] La femme représente pour nous la faiblesse, elle est exclue du monde masculin, celui des vainqueurs $^{73}$ ". Sans aller jusqu'à valider complètement la thèse de Patricia Smart, selon laquelle la littérature nationaliste des années 1960 ravalait l'ensemble des femmes au statut de putains, d'ennemies traîtresses ou de mères ${ }^{74}$, il faut lui concéder que les écrivains de Parti pris écrasaient souvent les femmes dans l'entreprise de libération nationale elle-même ${ }^{75}$. Elles étaient régulièrement décrites dans les nouvelles (mais point tellement dans les essais) en termes peu louangeurs, sinon franchement odieux. Par exemple, une nouvelle d'André Major décrit la tentative de strangulation de Judith par un héros qui s'imagine que cette "salope" l'empêche de faire la révolution ${ }^{76}$. Jacques Renaud, dans Le cassé, met en scène une symbolique nationale dans le viol d'une femme: «Philomène a crié en écartant les jambes, le sexe a percé le slip rose, la déchirure s'effiloche comme s'effiloche un drapeau déchiré. [...] Victoire Conquête! Avant d'la tuer ch-couche avec! Hip hip hip! Duplessis!

$$
++
$$

72. Voir Sréphanie LANTHIER, "L’impossible réciprocité des rapports politiques et idéologiques entre le nationalisme radical ec le féminisme radical au Québec, 1961-1972 ", mémoire de maîtrise, Département d'histoire, Université de Sherbrooke, 1998.

73. Laurent GIROUARD, "Blues pour un homme averti", Parti pris, vol. 1, n 8 , mai 1964, p. 58. Girouard résume un livre de Claude Jasmin qui parle d'un prolétaire québécois à la recherche de son père. Pierre MAHEU résumera, pour sa part, le propos de La ville inhumaine, du même Laurent Girouard, comme l'histoire d'un personnage minable qui n'a pas le droit à l'existence parce que son père est absent. "La mère, dans cet univers, n'est que présence de l'obligation morale éternelle, même l'amour par son intermédiaire se réduit à un devoir." Quant à l'amour charnel, comme il ne peur se réaliser avec la femme idéale ex pure, celle d'avant le péché originel, il n'arrive à se consommer qu'avec des prostituées ( $A$ À propos de La ville inhumainen, Parti pris, vol. 1, $n^{\circ} 8$, mai 1964, p. 59-61).

74. Voir Patricia SMART, Ecrire dans la maison du père, Montréal, Québec Amérique, 1988.

75. Voir Loti SAINT-MARTIN, Contre-voix. Essais de critique au féminin, Québec, Éditions Nuit Blanche, 1997, en particulier "Mise à mort de la femme ex "liberation" de l'homme: Godbout, Aquin, Beaulieu", p. 73-109. Suzanne PARADIS constate une semblable détérioration de la figure parernelle dans les romans écrits par des femmes (Femme fictive, femme reelle: personnage féminin dans le roman féminin canadienfrançais, 1884-1966, Québec, Garneau, 1966). Des écrivains féminins n'hésitaient pas à conforter à leur manière les thèses des partipristes. Un texce de Michèle LALONDE, "Le mythe du père dans la littérature québécoise" (Interprétation, vol. 3, $\mathrm{n}^{\mathrm{\alpha s}}$ 1-2, janvier-juin 1969, p. 215-226), a été longuement commenté (p. 227-245) par Hubert Aquin, Gérald Godin et Jacques Godbout.

76. André MAJOR, "Comme une perite boue humaine", Parti pris, vol. 1, n ${ }^{\circ}$ 5, février 1964, p. 40-42. Dans La corde au cou de Claude JASMIN, le héros déclare: "Je la tuerai, cout comme j’ai fait avec l'autre. Cette putain. Cette Suzanne. Toutes les mêmes" (Paris, Robert Laffont, 1961, p. 33). Dans Le couteau sur la table de Jacques GoDBOUT (Paris, Editions du Seuil, 1965), le protagoniste du roman tue Patricia, une Anglaise, pour s'exorciser lui-même et accéder à l'existence. 
$M^{\prime}$ as t'enculer avec ma matraque, chârogne ${ }^{77}$ !» Le rapport entre les sexes demeurait donc extrêmement trouble dans la littérature partipriste. Sous la plume des romanciers et des poètes, les rêveries sadomasochistes, nécrophiles, meurtrières et perverses rendent compte des tourments subconscients des colonisés. En affirmant que les hommes canadiens-français pourraient habiter pleinement leur identité masculine bafouée seulement quand ils seraient en mesure de rompre avec "une société "féminisée", vouée à l'attente, la docilité, la passivité et la vassalité ${ }^{78}$ ", les auteurs de Parti pris envoyaient un message ambigu: ils livraient une guerre au gynécée canadienfrançais tout en cherchant à se rapprocher des femmes ${ }^{79}$.

À cette époque, l'idéologie dominante du monde occidental faisait peu de place au "deuxième sexe». Cependant, une clef explicative plus circonstancielle de cette marginalisation et minorisation des femmes chez les partipristes loge dans la composition même de leur groupe. Ces jeunes avaient été éduqués, dès la puberté, dans les collèges classiques d'où les femmes se trouvaient exclues ${ }^{80}$. Leur camaraderie entretenait par sa composition même une fermeture aux femmes. Les collaborateurs du numéro spécial de La Barre du jour invités, en 1972, à parler de Parti pris étaient tous des hommes: Roger Soublière, Luc Racine, Patrick Straram, ainsi que vingt autres collaborateurs. Sur les trente-cinq noms cités aux colonnes rédaction, administration et collaboration du dernier numéro, celui de l'été 1968 , ne se retrouve qu'une seule femme, Huguette Corbo, affectée aux tâches de secrétariat. Ces intellectuels entonnaient spontanément entre eux le refrain des Copains d'abord. Les chansonniers de la rive gauche française, de Georges Brassens à Jacques Brel en passant par Léo Ferré, ne se gênaient pas pour tomber parfois dans la misogynie et leurs disciples québécois approuvaient d'autant plus leur éloge de l'amitié qu'ils étaient parvenus à l'âge où l'on

$$
++\div
$$

77. Jacques Renaud, Le cassé, Montréal, Éditions Parti Pris, 1964, p. 45 et 72.

78. Paul ChamberLAND, "De la damnation à la liberté, op. cit., p. 77.

79. Voir Kacherine A. ROBERTS, «Making Women Pay: Revolution, Violence, Decolonizing Quebec in Hubert Aquin's Trou de mémoire", Quebec Studies, vol. 30, 2000, p. 17-27; Diane LAMOUREUX, "Nationalisme et féminisme: impasse et coïncidences", Possibles, vol. 8, $\mathrm{n}^{\circ} 1,1983$, p. 43-59; L'amère patrie. Féminisme et nationalisme dans le Quebec contemporatn, Montréal, Éditions du remue ménage, 2001 ; Lise GAUVIN, "Littérature ec nationalisme: une question piégée, pourtanc inévitable", Possibles, vol. 8, $\mathrm{n}^{\circ} 1,1983$, p. 71-84; Chantal MAILLE, "Les groupes de femmes et la question nationale au Québec", Michel SARRA-BOURNET ex Jocelyn SAINT-PIERRE (dir.), Les nationalismes au Québec du XIX au XXF siècle, Québec, Presses de l'Université Laval, 2001, p. 145-152.

80. Louise BIENVENUE et Christine HUDON, "Entre franche camaraderie et amours socratiques. L'espace trouble ex ténu des amitiés masculines dans les collèges classiques (1870-1960)", Revue d'bistoire de l'Amérique française, vol. 57, $\mathrm{n}^{\circ} 4$, printemps 2004, p. 486. 
cherche justement à se liberer d'une famille sans chercher encore à fonder un foyer.

Les déclarations des partipristes au sujet de la répression sexuelle au Québec doivent ainsi être analysées en prenant en compte l'âge de ces révolutionnaires en herbe ${ }^{81}$. Leur quête d'indépendance envers leurs parents et leur recherche d'expériences sexuelles s'inscrivaient dans le moment qui sépare la sortie de l'école et l'entrée dans la vie active et conjugale ${ }^{82}$. Il était dès lors normal pour eux, en conformité avec les attentes de leur cohorte générationnelle, de mélanger leur propre désir d'émancipation (qui passait par le firt, la bière et les chansonniers, avant de se durcir, à la fin des années 1960 , dans le triptyque «sex, drugs \& rock ' $n$ roll») et leur aspiration nationale. L'idée d'épater les bourgeois en se promenant avec un livre sulfureux sous le bras, en consommant des substances illicites ou en séduisant des filles suit une pente historique qui va d'Honoré de Balzac à Karl Marx, de la cigarette au LSD et de quelques firts inoffensifs aux orgies. Ainsi, en partie au moins, la rhétorique freudienne et marxiste des partipristes masquait une révolte adolescente plutôt banale. Malgré leurs appels à la révolution et leur appui au FLQ, ils restaient des enfants assez sages quand il s'agissait de promouvoir une sexualité plus libre, n'évoquant jamais, par exemple, le caractère de "ville ouverte" de Montréal, ni ses cabarets, ses bars et ses bas-fonds ${ }^{83}$. Ils s'en tenaient à la Hutte espagnole, à La Paloma et à des cafés du même genre, tentant seulement de prolonger un peu la vie de collégiens avant d'assumer des responsabilités familiales. Loin de vouloir vivre une sexualité déviante, ils cherchaient à normaliser un ordre sexuel qui les consacrerait mâles dominants.

Les partipristes n'étaient pas différents de Pierre Vallières qui, dans le tout dernier paragraphe de son livre Nègres blancs d'Amérique, invoquait une nécessaire unité des travailleurs et des étudiants du Québec en

$+4+$

81. "Il y avait aussi, bien sûr, nos tics de révolutionnaires en herbe, nos vulgarités gratuites, une certaine façon de considérer la vie comme une aventure grave dont il ne fallait pas abandonner la conduite aux aînés" (André MAJOR, "Grandeur et misère de la jeunesse", Le Devoir, 30 décembre 1967, p. 14).

82. Voir Louise BIENVENUE et Christine HUDON, " "Pour devenir un homme, tu transgresseras..." Quelques enjeux de la socialisation masculine dans les collèges classiques québécois (1880-1939) ", The Canadian Historical Review, vol. 86, $\mathrm{n}^{\circ} 3$, seprembre 2005, p. 485-511.

83. Voir William WeinTRauB, City Unique: Montreal Days and Nights in the 1940s and 50s, Toronto, McClelland and Srewart, 1996; Will STRAW, "Montréal Confidential: Notes on an Imagined City", CineAction, $\mathrm{n}^{\circ}$ 28, printemps 1992, p. 58-64; Daniel ProvlX, Les bas-fonds de Montréah Moncréal, VLB éditeur, 1998; Danielle LACASSE, La prostitution féminine à Montréal, 1945-1970, Montréal, Boréal, 1994; Viviane NAMASTE, C'etait du spectacle! L'bistoire des artistes transsexuelles à Montréal, 1955-1985, Montréal, McGill-Queen's University Press, 2005; Daniel ProvLX, Le Red Light de Montréah Montréal, VLB éditeur, 1997. 
s'adressant d'abord à ses chums: «Eh! Georges, qu'est-ce que tu attends pour te décider? Et vous autres, Arthur, Louis, Jules, Ernest? Debout, les gars et tous ensemble: au travail! On prendra un autre verre de bière quand on aura fait plus que de discuter et de mettre le blâme toujours sur les autres ${ }^{84} "$. Ce n'est qu'à la fin des années 1960 que commencèrent à disparaître, dans le discours révolutionnaire dominant, les plus lourds accents machistes perceptibles dans les premiers numéros de Parti pris et que la doxa intellectuelle intégra, entre autres, les idéaux du Front de libération des femmes du Québec ${ }^{85}$. Il aura fallu la dissolution de la revue pour que les partipristes absorbent la prose de Simone de Beauvoir ainsi que celle des autres féministes européennes et américaines (dont Betty Fridan, auteure de The Feminin Mystic en 1963, ainsi que les féministes marxistes françaises), qu'ils connaissaient pourtant depuis quelques années, et renouent avec un courant féministe québécois qui comptait déjà à ce moment plusieurs faits d'armes (dont les combats menés par Marie Gérin-Lajoie et Thérèse Casgrain).

Le code de virilité en vigueur parmi les partipristes mettait de l'avant une camaraderie bruyante et vigoureuse. En revanche, il n'était pas question d'adopter des comportements qui auraient pu porter à équivoque. L'homosexualité, sans être condamnée en soi, était stigmatisée dans la mesure où elle paraissait une conséquence pathologique de l'aliénation collective $e^{86}$. Par voie de conséquence, plus la socialité entre copains était intense, plus ces derniers ressentaient le besoin de se dédouaner de cette accusation possible. Pierre Vallières (qui se réconciliera bien des années plus tard, quoique difficilement, avec son homosexualité) n'écrivait-il pas alors des odes à sa bienaimée, jouant dans ses poèmes le registre de la conquête de la femme-terre promise sur le mode accepté de l'hétérosexisme? Il est intéressant de noter que ceux qui partaient travailler à Ottawa, ville phallocratique par excellence, étaient accusés d'homosexualité. En se donnant au fédéral, ils commettaient une transgression sexuelle. Le célibat un peu louche de Pierre Elliott Trudeau

$$
+++
$$

84. Pierres VAllitres, op. cit., p. 289.

85. Voir Marrine LANCTOT, "La genèse et l'évolution du mouvement de libération des femmes à Montréal, 1969-1979 ", mémoire de maîtrise, Département d'histoire, Université du Québec à Montréal, 1980; Sean MILLS, "Québécoises debouce! Le Front de libération des femmes du Québec, le centre des fermmes ec le nacionalismen, Mens, vol. 4, $n^{\circ} 2$, printemps 2004, p. 183-210.

86. Voir Peter DICKINSON, Here is Queer: Nationalisms, Sexualities, and the Literatures of Canada, Toronto, University of Toronto Press, 1999. Sur le milieu homosexuel au Québec, lire Ross HigGiNs, De la clandestinité à l'affirmation. Pour une histoire de la communauté gaie montréalaise, Montréal, Comeau \& Nadeau, 1999; Pierre HURTEAU, "L'homosexualité masculine et le discours sur le sexe en contexte montréalais de la fin du XIX siècle à la Révolution tranquillen, Histoire sociale, vol. 26, n 51,1993 , p. 41-66. 
n'a-t-il pas nourri de folles rumeurs? La tenue de la Commission d'enquête sur le bilinguisme et le biculturalisme suscitait des propos sarcastiques: «La Confédérastie se fait embilinguer et biculer de jour en jour et de ville en ville $^{87}$ ". Ces "blagues" avaient beau ne pas trahir une "panique homosexuelle" dans le discours de la décolonisation au Québec, comme Robert Schwartzwald en fait l'hypothèse ${ }^{88}$ (puisque ce n'était pas l'homosexualité en soi qui posait problème, mais ce que l'homosexualité semblait révéler de la condition de l'homme québécois), elles n'en révélaient pas moins une réelle angoisse homophobe. Les partipristes ne voulaient pas que l'incapacité de voir dans les filles autre chose que des mères empêche certains hommes québécois de s'unir à des femmes et, par conséquent, leur fasse vivre leur homosexualité comme une maladie (infantile) découlant de leur condition colonisée.

Le message des partipristes demeure donc assez paradoxal, puisqu'ils alliaient une exigence révolutionnaire radicale à une morale bourgeoise plutôt convenue. La révolution faisait partie de la quête d'une «normalité" occidentale qui effacerait les tares affectant une société québécoise dominée et malade. "Ce qu'un jeune écrivain québécois devrait savoir, c'est qu'il ne pourra exercer sa sexualité de façon normale tant qu'il ne vivra pas dans un pays normal ${ }^{89}$ ". Il s'agissait donc, par l'adoption des canons sexuels qui prévalaient dans le reste du continent ${ }^{90}$, de viriliser une nation jugée trop féminine et une politique fédérale confondue avec un comportement pédéraste. Cette volonté de normativité et de conformité donnait aux appels à la révolte quelque chose d'ambivalent, le bouleversement des mœurs et des valeurs de l'ancien Canadien français ayant finalement pour objectif l'établissement d'une sexualité coulée dans le moule du discours nordaméricain dominant.

\section{UNE CONFRÉRIE RÉVOLUTIONNAIRE}

Parti pris s'est sabordé à l'automne 1968. À cette date, l'apparition du Mouvement souveraineté-association de René Lévesque (fondé en 1967) déchirait l'équipe rédactionnelle. Après avoir appuyé, en 1964, la création du

$$
+4+
$$

87. ANONYME, "Vulgarités", Parti pris, vol. 1, nos 9-10-11, été 1964, p. 174.

88. Robert SCHWARTZWALD, "La fédérastophobie, ou les lectures agirées d'une révolution tranquille", op. cit., p. 129-143.

89. Jacques GODBOUT, "Novembre 1971/Écrire», dans Le refformiste. Textes tranquilles, Montréal, Quinze, 1975, p. 157.

90. Voir Mary Louise ADAMS, The Trouble with Normal: Postwar Youth and the Making of Heterosexuality, Toronto, University of Toronto Press, 1997. 
Mouvement de libération populaire, qui s'était fondu dans le Parti socialiste du Québec en 1966 afin d'en former l'aile radicale, les collaborateurs se querellaient au sujet de la préséance des mots socialisme et indépendance ${ }^{91}$. Chez certains, le combat, s'éloignant des thèmes culturels, devenait beaucoup plus scientifique et politique, alors que pour d'autres, c'était justement l'inverse. Pour les partisans de la contre-culture, dont ceux derrière la publication de Mainmise, laquelle attira maints anciens partipristes, le privé apparaissait de plus en plus politique:

Les années d'après parti pris [sic] ont vu les jeunes de notre genre passer par une démarche qui ressemble plus à une conversion qu'à notre histoire de révolution - la "contre-culture", le Mouvement, l'Alternative; les thérapies, les drogues, le changement, la mutation, l'exploration des états de la conscience - visaient un changement personne ${ }^{92}$.

Pourtant, la question de la sexualité avait bien montré, dès les premiers numéros de Parti pris, que la psychologie individuelle des Canadiens français pouvait être directement liée au drame plus large d'une société dominée par les pouvoirs politiques anglais et les puissances économiques américaines.

Suivant le raisonnement des Pierre Maheu et consorts, les comportements sexuels, débordant une simple quête personnelle dans le sillage du projet de loi Omnibus de 1967, rejoignaient des enjeux révolutionnaires. Dans le Québec de l'époque, cette prise de position était assez novatrice, bien différente de l'approche, par exemple, de la revue Liberté qui, à l'hiver 1967, publiait un dossier spécial sur l'érotisme ${ }^{93}$. Dans ce dossier, le traitement de la sexualité restait à un niveau esthétique, les auteurs évoquant à peine au passage la question du colonialisme pour comprendre le récit du Cassé ou la narration de Pleure pas Germaine. Pour les collaborateurs de Parti pris, au contraire, la question sexuelle représentait une affaire publique, révolutionnaire. Certes, Marcel Rioux avait raison d'écrire que la contre-culture a davantage été vécue que théorisée par les partipristes ${ }^{94}$. Les aspects plus directement politiques ont été finement analysés, alors que les dimensions plus personnelles ont été évoquées dans les marges des réflexions sur le laïcisme, l'indépendantisme et le socialisme. Lidée d'inventer un

$$
+4+
$$

91. Voir Chantal GaGNON, "La revue "Parti Pris" en dialogue ", Le Carabin, 24 octobre 1968, p. 12.

92. Pierre MAHEU, "Postface", Un parti pris révolutionnaire, op. cit., p. 303.

93. Liberté, vol. 9, $n^{\circ} 6$, novembre-décembre 1967.

94. Marcel RIOUX, "Remarques sur le phénomène Parti pris", op. cit., p. 8. 
«nouvel amour» est restée plutôt en marges de leurs réflexions plus radicales, avant de surgir de manière plus manifeste dans leurs écrits de la décennie suivante. Il n'en demeure pas moins que le "parti pris sexuel" a constitué un aspect central, au moins implicitement, de leur réflexion décolonisatrice. En adoptant une perspective globale, les artisans de la revue ont voulu situer la question de la sexualité dans la trame historique de leur société et ont cherché à en comprendre les tenants et les aboutissants à partir d'une critique sociale et politique. Voilà qui demeure, encore aujourd'hui, et en dépit d'une trame historique et nationale qui répète des motifs communs aux discours nord-américains de l'époque ${ }^{95}$, une perspective critique originale.

Par ailleurs, la révolution sexuelle a eu lieu au Québec sans l'obtention de l'indépendance, ce qui donne maintenant des discours des partipristes l'impression qu'ils appartiennent à un passé antédiluvien. L'utopie qui associait en ces années ferventes un mouvement politique à un "mouvement de genre" paraît désormais pour le moins saugrenue, d'autant qu'elle véhiculait un machisme, une homophobie et un grégarisme masculin qui débouchaient sur une pernicieuse violence contre les femmes. Il y aurait une recherche de longue haleine à mener, qui permettrait de lier la pensée partipriste à l'importante chaîne de celles qui l'ont précédée, et qui viserait à dégager comment l'univers politique a sans cesse été défini au Québec en termes masculins, comme si la valorisation de l'action et du fait était par excellence une qualité mâle. Les Patriotes évoquaient la naissance d'une République composée d'égaux au moment même où ils abolissaient le droit de vote des femmes, et, plus près de nous, dans les années 1930, l'appel à une religion plus dynamique conduisit les jécistes et les jocistes à entreprendre un travail de virilisation de la foi et à rompre avec une spiritualité de bigotes et de saintes nitouches. En ce sens, les écrivains de la lignée de Parti pris ne faisaient que continuer une tradition ancienne qui, en découpant les sphères privée et publique à même le tracé supposé des genres, ne voyait de libération possible pour les hommes que dans une sortie définitive hors de la maternité. Les motifs patriarcaux de la "gang" de Maheu auraient ainsi reproduit des mobiles anciens en recouvrant d'un vernis freudo-marxiste une vision profondément masculiniste de la société qui, inconsciemment, cherchait peutêtre moins à favoriser l'épanouissement de tous qu'à rétablir au profit des hommes l'inégalité des sexes. Pour ces écrivains révolutionnaires, recondui-

$$
++
$$

95. Voir Andrew Parker, Mary Russo, Doris SOMMeR et Patricia YAEGer (dir.), Nationalisms of Sexualities, New York et Londres, Routledge, 1992. 
sant un topos que l'on retrouve chez d'autres auteurs influents de leur époque ${ }^{96}$, la perversion ultime du Canada français, n'était-ce pas que les femmes puissent dominer les hommes? Leur volonté de chambardement de l'ordre établi ressemblait davantage, de ce point de vue (qui n'exclut pas une pléiade d'autres aspects beaucoup plus positifs), à une normalisation de la sexualité québécoise qu'à sa réinvention sur des bases nouvelles, désormais parfaitement égalitaires. En d'autres termes, il s'agissait moins d'établir des liens d'amour que de remodeler les relations de genres sur des bases phallocratiques, homosociales et narcissiques. Comme révolution, on a déjà vu mieux.

96. Lire par exemple Gwen BERGNER, "Who is that masked woman? Or, the role of gender in Fanon's Black Skin, White Masks", PMLA, vol. 110, n 1, p. 75-88. 